\title{
Kinesthetic aftereffect: One phenomenon or two?
}

\author{
A. HARVEY BAKER \\ Queens College of the City University of New York, Flushing, New York \\ BRIAN L. MISHARA \\ Université du Québec à Montréal, Montréal, Quebec, Canada
}

and

IRENE W. KOSTIN

Educational Testing Service, Princeton, New Jersey

\begin{abstract}
Kinesthetic (figural) aftereffect (KAE) studies almost always involve an aftereffect-inducing stimulus (I) that is wider or narrower than the test stimulus $(T) . I \neq T$ has been presumed to be a necessary condition for KAE's occurrence. We contend that this, in part, reflects researchers' failure to use an appropriate control condition (here, $\mathrm{I}=\mathrm{T}$ ): Effects due to size difference and effects due to induction per se have been confounded. In a new study, which explored the relationships of $\mathrm{I}>\mathrm{T}$ and $\mathrm{I}<\mathrm{T}$ relative to an $\mathrm{I}=\mathrm{T}$ control condition, $\mathrm{I}<\mathrm{T}$ did, but $\mathrm{I}>\mathrm{T}$ surprisingly did not, differ from $\mathrm{I}=\mathrm{T}$. Two different $\mathrm{KAE}$ phenomena apparently exist: an aftereffect induction phenomenon and a contrast effect. There is also an effect for the $\mathrm{I}=\mathrm{T}$ condition of decrease in width judgments.
\end{abstract}

Is there a single, contrast-type of kinesthetic aftereffect (KAE) or is there more than one type of effect involved in KAE? Earlier researchers apparently assumed that a size difference between the aftereffect-inducing stimulus (I) and the standard test stimulus ( $T$ ) was a necessary condition for KAE's occurrence. They thus described KAE as a "contrast effect." In this paper, we explore the possibility that KAE might be due both to a size difference between $I$ and $T$ and to the effect of induction per se.

\section{The Kinesthetic Aftereffect Task}

Koehler and Wallach's (1944) classic paper on visual aftereffects sparked widespread interest in aftereffect phenomena-an interest that has persisted to the present (e.g., Cowart-Steckler \& Pollack, 1982; Harris, 1982; Huppert \& Singer, 1967; Singer \& Collins, 1972; Skowbo \& White, 1983; Wenderoth, 1970; Wilson, 1965). Kinesthetic aftereffect (sometimes referred to as "kinesthetic figural aftereffect") has also continued to be of interest (e.g., Bakan \& Thompson, 1967; Herzog \& Weintraub, 1977, 1982; Pollack, 1963a; Walker, 1978; Walker \& Shea, 1974; Wertheimer \& Sheets, 1968).

KAE refers to changes in the judged width of a standard test block $(T)$ following inspection (usually rubbing) of an aftereffect-inducing block (I). Typically, a subject

We thank Scott Tempel, who served as experimenter. This study was supported in part by National Institute of Child Health and Human Development Grant 5 PO1 HDQ 1762 to the Research Division at Educational Testing Service. Reprints may be obtained from A. H. Baker, whose mailing address is: Department of Psychology, Remsen Hall 120, Queens College, Flushing, NY 11367. holds $\mathrm{T}$ in one hand and moves his or her other hand along a wedge-shaped comparison block until he or she feels that the width of the wedge equals the width of $T$. These width judgments are repeated after one or more induction periods during which the subject rubs an I block, which is almost always wider or narrower than T. Generally, if $\mathrm{I}>\mathrm{T}$, judgments are smaller after induction(s); and if $\mathrm{I}<\mathrm{T}$, judgments are larger (e.g., Bakan \& Thompson, 1967; Pressey, 1965, 1967).

Although the term "contrast effect" has been used to describe such phenomena in various modalities, there is no generally accepted perceptual or psychophysiological theory of aftereffect phenomena. Alternative explanations include: satiation theory (Koehler \& Wallach, 1944), frame of reference (Helson, 1964), cortical inhibition (Eysenck, 1955), statistical theory (Osgood \& Heyer, 1952), and sensory tonic theory (Pollack, 1963b). As for KAE, at best one can list a set of factors that affect its magnitude. (See review by McEwen, 1958.)

\section{Rationale for This Study}

Prior researchers have apparently assumed that a necessary and sufficient condition for producing a KAE is a difference in size between I and T. However, to determine if a size difference between $I$ and $T$ (i.e., $I \neq T$ ) is essential for producing an aftereffect, one must first directly compare (1) $I \neq T$ conditions with (2) a control condition, which assesses the effects, if any, of the induction procedure itself, apart from any size difference. One would have expected that so basic a comparison would have been undertaken very early in the course of 
KAE research. However, to the best of our knowledge, no study both used a control condition designed to assess the effects of induction per se and made a direct statistical comparison between an $I \neq T$ condition and such a control condition. Although it is clear from the literature that the KAE for I $>\mathrm{T}$ differs from the KAE for I $<\mathrm{T}$, without an appropriately defined control condition that assesses the effects of the induction procedure itself, we cannot say whether this difference is entirely due to $\mathrm{I}>\mathrm{T}$, to $I<T$, or to both. Perhaps only one of these $I \neq T$ conditions results in a KAE that is different from that of such a control condition. If such were the case, then one would have to conclude that there was a contrast effect for only one of the $I \neq T$ conditions, because the KAE for the other $I \neq T$ experimental condition did not differ from that of the control condition (which assessed the effects due to induction, apart from any size difference).

A control condition that assesses the effects of induction alone must be identical to the experimental condition in every respect except for the particular variable under study. In studies comparing $\mathrm{I}>\mathrm{T}$ and $\mathrm{I}<\mathrm{T}$, the independent variable involves inspecting an I block that differs in size from $\mathrm{T}$. We believe that an $\mathrm{I}=\mathrm{T}$ condition (a same-size block condition) satisfies this control condition requirement because it is identical to the $I \neq T$ conditions in all respects except that there is no difference in size between I and T.

It is relatively rare to find a KAE study in which the effects of $I>T$ and $I<T$ were each studied and compared. None of the few studies that employed typical KAE procedures and included both $\mathrm{I}>\mathrm{T}$ and $\mathrm{I}<\mathrm{T}$ conditions (Gardner, 1961; Hilgard, Morgan, \& Prytulak, 1968; Weintraub, Green, \& Herzog, 1973) also included an $I=T$ condition.

Some previous KAE studies have used a No-I control condition in which the subjects simply rested their hands during the induction period (e.g., Bakan, Meyers, \& Schoonard, 1962; Carlson, 1963; Gardner, 1961). Because a No-I control condition does not assess effects due to the induction procedure itself, aside from the size difference, the No-I condition does not help in resolving the issue posed at the start of this paper: Is $I \neq T$ necessary for the production of a KAE? However, a No-I control condition which assesses practice effects in making size judgments over time would be useful in helping to answer other problems in the KAE area (as we illustrate later in this paper).

Some may object that what we are proposing is not new: Five prior studies have used an $I=T$ condition (Charles \& Duncan, 1959; Dinnerstein, Lowenthal, Marion, \& Olivo, 1962; Jaffe, 1956; Pollack, 1963a; Pressey, 1967). Our response is threefold. First, two of these studies (Dinnerstein et al., 1962; Jaffe, 1956) employed neither I > T nor I $<$ T KAE conditions, so none of the issues of concern here could be addressed. Second, although Pollack (1963a) included $\mathrm{I}>\mathrm{T}, \mathrm{I}<\mathrm{T}$, and $\mathrm{I}=\mathrm{T}$ conditions, $\mathrm{I}=\mathrm{T}$ was not used as a control or comparison condition. Rather, the effects of pulling the fingers together versus apart by applying external force to them (a very unusual procedure in KAE studies) were studied for $\mathrm{I}>\mathrm{T}$, for $\mathrm{I}<\mathrm{T}$, and for $\mathrm{I}=\mathrm{T}$. The $\mathrm{I}=\mathrm{T}$ results were analyzed separately from the other two conditions, and no statistical comparisons of any kind were undertaken between $\mathrm{I}=\mathrm{T}$ and either $\mathrm{I}>\mathrm{T}$ or $\mathrm{I}<\mathrm{T}$. Third, two studies (Charles \& Duncan, 1959; Pressey, 1967), which addressed problems other than that of focal interest here, each used $\mathrm{I}>\mathrm{T}$ and $\mathrm{I}=\mathrm{T}$. These studies were well designed in terms of the issues to which they were adressed. In terms of the focal issue we wish to address, however, they show certain limitations: (1) neither study used I $<\mathrm{T}$, and (2) although the total sample size of each study was considerable, the sample was subdivided into many conditions, with small sample size for $\mathrm{I}=\mathrm{T}$.

\section{METHOD}

\section{Apparatus}

The rectangular-shaped T block was 2 in. $(5.08 \mathrm{~cm})$ wide. A 30in. $(76.20-\mathrm{cm})$-long tapered comparison wedge was used, and three different rectangular-shaped aftereffect-inducing (I) blocks: 2.5 in. $(6.35 \mathrm{~cm})$ wide $(I>T) ; 1.5$ in. $(3.81 \mathrm{~cm})$ wide $(I<T)$; and $2.0 \mathrm{in} .(5.08 \mathrm{~cm})$ wide $(I=T)$. $T$ and $I$ blocks were always to the subject's left, and the wedge was always to her right, with its wider end in front of her. During testing, the subject wore a large cardboard collar which prevented her from seeing the apparatus. The subject stood between two 28.25-in. (71.8-cm)-high tables, on which the blocks were set.

\section{Procedure}

The procedures were closely patterned after a KAE study by Weintraub et al. (1973). The subject first felt the length of the wedge from the narrow end, where the ascending trials later began, toward the wide end up to the point where the descending trials would begin. Then she made two practice judgments of T's width, by holding $T$ between the thumb and forefinger of the left hand and simultaneously indicating the apparent width of $T$ on the tapered wedge with the thumb and forefinger of the right hand. After this, the subject made four preinduction judgments of T's width. On half of the trials, the subject began her judgments at the narrow end of the wedge (ascending judgments), which was $10.8 \mathrm{in}$. $(27.4 \mathrm{~cm})$ away from the point of objective equality (POE). On the other trials, the subject began at a point toward the wide end of the wedge (descending judgments), also 10.8 in. $(27.4 \mathrm{~cm}$ ) away from the POE. By mounting the wedge in a track on the table, the POE could be moved $2.5 \mathrm{in} .(6.35 \mathrm{~cm})$ forward and $2.5 \mathrm{in} .(6.35 \mathrm{~cm})$ back with respect to the subject's body. The sequence for the four pretest trials was: ascending/wedge back, descending/wedge forward, descending/wedge back, and ascending/wedge forward. This exact sequence was also used for each of the two sets of four postinduction trials.

The four preinduction trials were followed by two successive intervals of 60 -sec aftereffect induction. During these times, each subject rubbed one of the three I blocks with the thumb and forefinger of her left hand, and rested the right hand at her side. After each induction interval, the T block was replaced in the subject's left hand and she made four postinduction judgments (eight postinduction judgments in all). The subjects were told to make their judgments as quickly and as accurately as they could, and the actual time taken by each subject for each trial was measured. The experimenter, a male, was uninformed as to the purpose and hypotheses of the study.

\section{Scores}

The basic data were the subject's width judgments (in millimeters) as indicated by her showing where the width of the wedge was felt to be equal to that of the $T$ block. The means of the four preinduction judgments and of the eight postinduction judgments were computed for each subject. In addition, a KAE score for each subject 
was obtained by subtracting the preinduction mean from the postinduction mean. Measurement accuracy, using identically designed apparatus and similar procedures in 11 samples, has proven to be satisfactorily high, as indexed by internal consistency correlations (Mishara \& Baker, 1978).

\section{Experimental Conditions and Subjects}

The subjects were 108 right-handed female undergraduate paid volunteers, who were assigned randomly to one of the three experimental conditions: $\mathrm{I}>\mathrm{T}, \mathrm{I}=\mathrm{T}$, or $\mathrm{I}<\mathrm{T}$.

\section{RESULTS}

The data, expressed in terms of KAE scores, are presented in Figure 1. There are four issues that can be raised regarding these data.

1. To determine if the usual aftereffects for I $>\mathrm{T}$ and $\mathrm{I}<\mathrm{T}$ occur, we first evaluated the results for I $>\mathrm{T}$ and $\mathrm{I}<\mathrm{T}$ as these have been traditionally assessed. Significant aftereffects were obtained both for I $>\mathrm{T}$, where, as expected, the postinduction judgments $(M=$ $53.28 \mathrm{~mm} ; S D=5.08 \mathrm{~mm}$ ) were significantly smaller $[t(35)=3.80, p<.001$, two-tailed test $]$ than the preinduction judgments $(M=55.55 \mathrm{~mm} ; S D=4.18 \mathrm{~mm})$, and for $\mathrm{I}<\mathrm{T}$, where the postinduction judgments $(M=$ $55.18 \mathrm{~mm} ; S D=3.86 \mathrm{~mm}$ ) were significantly $[T(35)=$ $3.22, p<.005]$ larger than the preinduction judgments $(M=53.58 \mathrm{~mm} ; S D=4.26 \mathrm{~mm})$. Since these two significant outcomes are in opposite directions, clearly I $>\mathrm{T}$ and $\mathrm{I}<\mathrm{T}$ differ from each other.

2. We explored whether the traditional approach would show a significant aftereffect for the $I=T$ condition. The results show that the postinduction judgments $(M=$ $53.01 \mathrm{~mm} ; S D=4.12 \mathrm{~mm}$ ) for $\mathrm{I}=\mathrm{T}$ were significantly $[t(35)=2.22, p<.05$, two-tailed test $]$ smaller than the

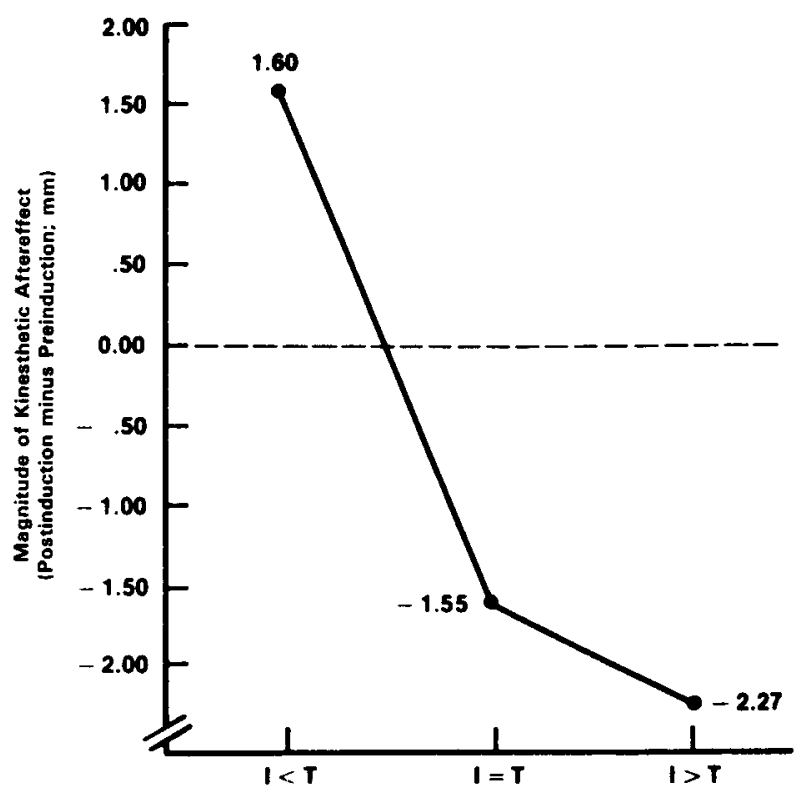

Figure 1. Observed kinesthetic aftereffect as a function of the relationship between the size of the inspection block (I) and the standard test block (T). preinduction judgments $(M=54.56 \mathrm{~mm} ; S D=$ $4.81 \mathrm{~mm})$.

3. We then considered what our $I=T$ controlcondition approach showed. Results from a $3 \times 2$ ANOVA, with type of block $(\mathrm{I}>\mathrm{T}$ vs. $\mathrm{I}=\mathrm{T}$ vs. $\mathrm{I}<\mathrm{T})$ as the independent groups factor and testing occasion (preinduction vs. postinduction judgments) as the repeated measures factor, showed a significant interaction for condition $\times$ occasion $[F(2,105)=11.68, p<.001]$. This indicated that the aftereffect does vary as a function of block size.

To follow up this last analysis, we now considered KAE scores rather than the separate preinduction and postinduction scores. To ascertain whether $\mathrm{I}<\mathrm{T}$ and $\mathrm{I}>\mathrm{T}$ each differed from $\mathrm{I}=\mathrm{T}, t$ tests for independent groups were undertaken. The outcome for $\mathrm{I}<\mathrm{T}(M \mathrm{KAE}=$ $1.60 \mathrm{~mm} ; S D=3.00 \mathrm{~mm}$ ) did differ significantly $[t(70)=3.74, p<.001]$ from that observed for $\mathrm{I}=\mathrm{T}$ $(M \mathrm{KAE}=-1.55 \mathrm{~mm} ; S D=4.18 \mathrm{~mm})$. However, there was no significant difference $[t(70)=0.79$, n.s. $]$ between the aftereffect obtained for I $>\mathrm{T}(M \mathrm{KAE}=$ $-2.27 \mathrm{~mm} ; S D=3.60 \mathrm{~mm}$ ) and the aftereffect obtained for $\mathrm{I}=\mathrm{T}$.

4. The surprising finding is that the KAE for $\mathrm{I}>\mathrm{T}$ was not significantly greater than that for $\mathrm{I}=\mathrm{T}$. If, for some reason, the subjects in the I $>\mathrm{T}$ group took substantially longer to complete their postinduction trials, this might have led to greater aftereffect dissipation (see, e.g. , Bourne, Kepros, \& Beier, 1963), which could account for the failure to observe a significant difference between $\mathrm{I}>\mathrm{T}$ and $\mathrm{I}=\mathrm{T}$. In fact, the subjects in $\mathrm{I}>\mathrm{T}$ took a shorter time $(M=7.9 \mathrm{sec}, S D=3.4 \mathrm{sec})$, although not significantly so, than did the subjects in $\mathrm{I}=\mathrm{T}(M=$ $9.5 \mathrm{sec}, S D=6.2 \mathrm{sec}$ ). Thus, these findings do not reflect any artifact introduced by differences in subjects' judgment time between conditions.

\section{DISCUSSION}

\section{I $>\mathbf{T}$ and $\mathbf{I}<\mathrm{T}$}

The central question underlying the present study was, "Is new light shed on the effects associated with $I>T$ and $\mathrm{I}<\mathrm{T}$ when an $\mathrm{I}=\mathrm{T}$ control condition is used to provide appropriate 'baseline' data?" To explore this issue, we consider the results first as they might be treated in a "traditional" $\mathrm{KAE}$ study in which no $\mathrm{I}=\mathrm{T}$ control condition baseline was included. Here, it can simply be noted that, as in earlier studies (1) size judgments decreased from preinduction to postinduction trials for I $>\mathrm{T}$ and increased for $\mathrm{I}<\mathrm{T}$, and, of course, (2) the two conditions differed from each other.

Now, let us contrast this traditional treatment with the view that emerges when the same results are considered from the perspective of the $I=T$ control condition. The KAE score (that is, the difference between pre- and postinduction scores) for $\mathrm{I}<\mathrm{T}$ showed an increase of $+1.60 \mathrm{~mm}$. This value differed by $3.15 \mathrm{~mm}$ from the KAE score of $-1.55 \mathrm{~mm}$ observed for the baseline data 
of the $\mathrm{I}=\mathrm{T}$ control condition. Expressed in terms of $\mathrm{Co}-$ hen's (1969) $d$ statistic, there was a $.87 S D$ difference between the two conditions, indicating a large betweencondition difference according to Cohen.

However, the I > T effect (which looked like the more robust effect when no baseline was used) did not differ significantly from $\mathrm{I}=\mathrm{T}$ (a $.72-\mathrm{mm}$ difference between conditions). In terms of Cohen's $d$, there was only a 0.18 $S D$ difference between $\mathrm{I}>\mathrm{T}$ and $\mathrm{I}=\mathrm{T}$, a small effect. Furthermore, although $\mathrm{I}>\mathrm{T}$ seemed to produce a somewhat larger contrast effect than $I<T$ when $I=T$ was not considered, our findings indicated that the strong contrast effect actually occurs only with $I<T$ when the baseline was taken into account. Since the $I>T$ effect was not significantly different from $\mathrm{I}=\mathrm{T}$, the $\mathrm{I}>\mathrm{T}$ effect did not appear to be due to the size difference between induction and test stimuli. It can be parsimoniously explained as arising solely because of induction. That is, insofar as these data are considered, inspecting I $>\mathrm{T}$ added nothing not already observed with subjects who inspected $\mathrm{I}=\mathrm{T}$. These conclusions suggest that KAE, which was previously construed as being a single "contrast effect," involves two perceptual effects: an induction effect for $\mathrm{I}=\mathrm{T}$ and $\mathrm{I}>\mathrm{T}$ and a contrast type effect for $\mathrm{I}<\mathrm{T}$. $^{1}$

\section{An Additional Issue: The Findings for $I=T$}

Although the main goal of this study had been to determine whether there were effects for both $\mathrm{I}>\mathrm{T}$ and $\mathrm{I}<\mathrm{T}$ when the relevant $\mathrm{I}=\mathrm{T}$ control condition was used, it was also of interest to find that a significant decrease in size judgments occurred for $\mathrm{I}=\mathrm{T}$. Two questions arise: Is this $I=T$ effect replicable? Does this $\mathrm{I}=\mathrm{T}$ effect represent a true aftereffect or is it simply a practice effect?

Regarding replicability, there are eight samples from appropriately designed studies which reported on mean KAE for an $I=T$ condition. We first consider the six of these samples that employed typical KAE procedues, very similar to the type of procedures we used. Two of these samples come from a personality-type study (Dinnerstein et al., 1962), which did not assess whether KAE was significant. Each of the remaining four samples (Charles \& Duncan, 1959; Jaffe, 1956; and two from Pressey, 1965-also reported in 1967) reported that KAE for $I=T$ was nonsignificant. Apparently it was the lack of findings from these four latter samples with typical KAE procedures which provided the basis for the conclusion in the literature that there was no KAE for an $I=T$ condition (e.g., Weintraub \& Herzog, 1973).

The failure to obtain a significant effect for $I=T$ in the four samples just specified may indicate that there is no effect, but other explanations are also possible. The failure to observe such an effect may have occurred simply because these studies used small samples. (The sample sizes were $12,12,10$, and 20 for the two Pressey [1965, 1967], the Jaffe [1956], and the Charles and Duncan [1959] samples, respectively-an average of 13.5.)
If the effect for $I=T$ is less robust than that for $I \neq T$, where usually a sample of 20 to 25 will produce significant results, then a sample even larger than 20 to 25 would be needed. If our argument is correct, then the possibility of observing significance in these past studies should be considerably enhanced if one pooled the results across these studies, thereby rectifying, in a sense, the problem of small sample size. We therefore undertook a metaanalysis of these past studies.

If means and standard deviations (or exact values from $t$ or $F$ tests) were available for each of the above-specified six samples, one could then test the hypothesis that the $\mathrm{I}=\mathrm{T}$ condition resulted in an aftereffect on the basis of the total set of six samples. Unfortunately, only means were available for the two samples from Dinnerstein et al. (1962). Given our goal of assessing the outcome for all of these six $I=T$ samples, considered as a set, only a nonparametric meta-analytic procedure was possible. According to the null hypothesis of no effect for $I=T$, outcomes showing decreases and increases should occur with equal frequency. All six samples showed a decrease in size judgments from preinduction to postinduction trials. The exact probability of observing all six outcomes showing a decrease was .016 (one-tailed binomial test). (Since the question here was whether or not our finding of a decrease in size judgment for $\mathrm{I}=\mathrm{T}$ was consistent with the data reported in earlier studies, a one-tailed binomial test seemed appropriate.)

Now let us turn to the two of the eight samples that came from the study with very atypical procedures (Pollack, 1963a). This study involved the unique variable of exploring the effects of applying external pressure to passive and stationary fingers, held by wooden clamps, in terms of pulling the fingers either toward or away from each other. (The external-pressure variable proved to be so potent that the usual contrast effects found for I $>\mathrm{T}$ and I $<$ T did not manifest themselves.) Pollack (1963a) found an increase in size judgments for one $\mathrm{I}=\mathrm{T}$ sample and a decrease for the other. Since the meta-analytic method can give distorted results if samples that should be included are discarded for one reason or another, a conservative approach here indicated that the two Pollack (1963a) samples, despite considerable differences in method and outcome, should be included. The exact probability of observing seven outcomes showing decreases and one outcome showing an increase is .035 (one-tailed binomial test).

Suppose that we consider the outcome from this latter meta-analysis as constituting one test of the hypothesis that $I=$ T leads to a change in size judgments $(p=.035)$ and the outcome from the present $I=T$ condition as constituting another independent test of the same hypothesis (exact one-tailed $p=.019$ ). Following Rosenthal (1978), the result of combining probabilities here shows $p<.003$ (two-tailed test).

The contention that there is a replicable effect for $\mathrm{I}=\mathrm{T}$ in KAE is strengthened by the just-reported findings and by the fact that effects for $I=T$ conditions have been 
regularly found for other types of aftereffect, including: auditory pitch judgments (Christman, 1954), visual size judgments (Sagara \& Oyama, 1957), and auditory duration judgments (Huppert \& Singer, 1967).

Does this I $=\mathrm{T}$ effect reflect a true aftereffect, or might it simply be a pseudo-aftereffect that occurred as a result of practice? Practice effects have been documented in the KAE literature as occurring even when no aftereffect induction had been administered. That is, systematic changes in size judgments have been observed from preinduction to postinduction trials when all the subjects did was to make the preinduction and postinduction judgments and to simply rest their hands during the intervening time (e.g., Broadbent, 1961). It thus can be asked: Could the effect that we observed here for $I=T$ simply be the same type of practice effect?

In terms of the main focus of this paper-the need to employ an $\mathrm{I}=\mathrm{T}$ control condition when attempting to delineate the nature of the phenomena associated with I $>\mathrm{T}$ or I $<\mathrm{T}$-it makes no difference whether the effect found for $\mathrm{I}=\mathrm{T}$ represents a true KAE or a pseudo$\mathrm{KAE}$. As long as there is a significant effect for $I=T$, whatever its nature, there is support for our controlcondition argument.

In terms of gaining a better understanding of KAE, however, there would be considerable value in ascertaining whether the change observed for $\mathrm{I}=\mathrm{T}$ represented a true- or a pseudo-KAE effect. One basis for determining which alternative is more probable would be to compare the effects observed for the nine known $\mathrm{I}=\mathrm{T}$ samples (eight from the meta-analysis and one from the study reported here) with all known samples where no aftereffect induction (No I) was administered. Eleven such No-I samples are known to us-seven showed an increase from (1) the initial preinduction judgments to (2) the postinduction judgments, which were made after the handresting interval (Broadbent, 1961 [one of two samples]; Carlson, 1963 [two samples]; Gardner, 1961; Mishara \& Baker [unpublished data]; Weintraub et al., 1973; Weintraub \& Herzog, 1973) and four showed a decrease (Bakan et al., 1962; Broadbent, 1961 [the other of two samples]; Carlson \& Campbell, 1968; Pressey, 1965). We compared this outcome for No I (seven samples showed an increase and four showed a decrease) with that for $\mathrm{I}=\mathrm{T}$ (one sample showed an increase and eight showed a decrease) by computing Fisher's exact test. The probability of this outcome was $p<.05$ (two-tailed test). This outcome is inconsistent with the hypothesis that the same pseudo-KAE occasionally found for the No-I condition (which we presume reflects practice effects) also occurs for $I=T$, and thus offers support for the view that the observed effect for $I=T$ represents a true aftereffect. ${ }^{2}$

\section{CONCLUSIONS}

We have contended that because of failure to use an $\mathrm{I}=\mathrm{T}$ control condition, effects due to size differences and effects due to induction per se have not been distin- guished in the KAE literature. We therefore conducted a study comparing $\mathrm{I}>\mathrm{T}, \mathrm{I}<\mathrm{T}$, and $\mathrm{I}=\mathrm{T}$ conditions. When the results of $\mathrm{I}>\mathrm{T}$ and $\mathrm{I}<\mathrm{T}$ alone are considered, both conditions appear to show contrast effects, with the effect for I $>\mathrm{T}$ being perhaps somewhat more robust. However, when the results of $I>T$ and $I<T$ are evaluated from the perspective of the $\mathrm{I}=\mathrm{T}$ control condition, only I $<\mathrm{T}$ can be described as showing a contrast effect. Since the result for I $>\mathrm{T}$ does not differ significantly from that for $\mathrm{I}=\mathrm{T}$, the effects for both of these conditions can be parsimoniously described as constituting only an induction effect. This differs from the assumption in the earlier literature that there is only a single, contrast-type of KAE.

A secondary finding also emerged from this study: A significant aftereffect of decrease was observed for $\mathrm{I}=\mathrm{T}$. A meta-analysis of previously published data indicated that this effect was replicable. Although effects for $I=T$ conditions have been previously reported in other modalities, the present finding apparently represents the first evidence that such an effect holds for KAE when typical KAE procedures are employed. When the outcomes for the set of nine KAE samples run under $I=T$ are compared with the outcomes for the set of 11 samples run under a No-I condition, the results were inconsistent with the view that the decrease for $I=T$ represents a practice effect, thus buttressing the view that this decrease is a true aftereffect.

We conclude that KAE is not a single or unitary phenomenon. At least two types of KAE exist: A contrast effect due to size difference between $I$ and $T$ (for $\mathrm{I}<\mathrm{T}$ stimuli) and an induction effect (for $\mathrm{I}=\mathrm{T}$ and at least for certain I > T stimuli). Admittedly, "induction" and "size difference" are simply operational specifications of the difference between conditions and, as such, are very close to a descriptive label for these phenomena. No claim is made that we have specified the processes underlying such effects. We believe that the present results help to delineate KAE phenomena more accurately than has been the case in the past, and, therefore, these findings should provide a more solid basis for developing more adequate theoretical explanation(s) of these interesting effects.

\section{REFERENCES}

BaKan, P., Myers, L., \& Schoonard, J. (1962). Kinesthetic aftereffects and length of inspection period. American Journal of Psychology, 75, 457-461.

BAKAN, P., \& THOMPSON, R. (1967). Induction and retention of kinesthetic aftereffects as a function of number and distribution of inspection trials. Perception \& Psychophysics, 2, 304-306.

Bourne, L., KePros, P., \& Beier, E. (1963). Effect of post-inspection delay upon kinesthetic figural aftereffects. Journal of General Psy. chology, 68, 37-42.

Broadbent, D. E. (1961). Psychophysical method and individual differences in the kinesthetic figural aftereffect. British Journal of Psychology, 52, 97-104.

Carlson, J. B. (1963). Effect of amount and distribution of inspection time and length of decay interval on kinesthetic aftereffect. Journal of Experimental Psychology, 66, 377-382.

Carlson, J. B., \& CAMPBell, S. G. (1968). Influence of repeated testing 
and of starting position in kinesthetic aftereffect. Perceptual \& Motor Skills, 27, 247-253.

Charles, J., \& DunCan, C. (1959). The distance gradient in kinesthetic figural aftereffect. Journal of Experimental Psychology, 57, 164-170.

Christman, R. J. (1954). Shifts in pitch as a function of prolonged stimulation with pure tones. American Journal of Psychology, 67, 484-491.

COHEN, J. (1969). Statistical power analysis for the behavioral sciences. New York: Academic Press.

Costello, C., Beatriz, H., \& Holland, H. (1963). The role of the interpolating stimulus in producing kinesthetic figural aftereffects. American Journal of Psychology, 76, 670-674.

Cowart-Steckler, D., \& Pollack, R. (1982). The aftereffects of prolonged perception of shape. Bulletin of the Psychonomic Society, 20, 239-241.

Dinnerstein, A., Lowenthal, M., Marion, R., \& Olivo, J. (1962). Pain tolerance and kinesthetic aftereffect. Perceptual \& Motor Skills, 15, 247-250.

EYSENCK, H. (1955). Cortical inhibition, figural-aftereffect and theory of personality. Journal of Abnormal \& Social Psychology, 51, 94-106.

HARRIS, J. (1982). The VVIQ and imagery-induced McCollough effects: An alternative analysis. Perception \& Psychophysics, 32, 290-292.

Helson, H. (1964). Adaptation level theory. New York: Harper \& Row.

Herzog, T., \& Weintraub, D. (1977). Preserving the kinesthetic aftereffect: Alternating inducing blocks day by day. American Journal of Psychology, 90, 461-474.

Herzog, T., \& Weintraub, D. (1982). Roundup time at personality ranch: Branding the elusive augmenters and reducers. Journal of Personality \& Social Psychology, 42, 729-737.

Hilgard, E. R., Morgan, A. H., \& Prytulak, S. (1968). The psychophysics of the kinesthetic aftereffect in the Petrie block experiment. Perception \& Psychophysics, 4, 129-132.

HuPPERT, F., \& Singer, G. (1967). An aftereffect in judgment of auditory duration. Perception \& Psychophysics, 2, 544-546.

JAFFE, R. (1956). The influence of visual stimulation on kinesthetic figural aftereffect. American Journal of Psychology, 69, 70-75.

KoEHLER, W., \& WALLACH, H. (1944). Figural aftereffects: An investigation of visual processes. Proceedings of the American Philosophic Society, 88, 267-357.

Krauskopf, J., \& ENGEN, T. (1960). The distance-paradox in kinesthetic figural aftereffects. American Journal of Psychology, 37, 298-301.

McEwen, P. (1958). Figural after-effects. British Journal of Psychology, Monograph Supplements No. 31, Cambridge University Press.

MishaRA, B. L., \& BAKER, A. H. (1978). Kinesthetic aftereffect scores are reliable. Applied Psychological Measurement, 2, 239-247.

OsGOOD, C. E., \& HEYER, A. W. (1952). A new interpretation of figural after-effects. Psychological Review, 59, 98-118.

Pollack, R. (1963a). The aftereffects of passive kinesthetic-tactual stimulation of the thumb and forefinger. Acta Psychologica, 21, 17-23.

Pollack, R. (1963b). Application of the sensory-tonic theory of perception to figural aftereffect. Acta Psychologica, 21, 1-16.

Pressey, A. (1965). The distance gradient in visual and kinesthetic aftereffects. Unpublished doctoral dissertation, University of Alberta, Edmonton, Alberta.
Pressey, A. (1967). The distance gradient in the aftereffect of kinesthetic width judgment. Quarterly Journal of Experimental Psychology, 19. 43-48.

Rosenthal, R. (1978). Combining results of independent studies. Psychological Bulletin, 85, 185-193.

Sagara, M., \& OYAMA, T. (1957). Experimental studies on figural aftereffects in Japan. Psychological Bulletin, 54, 327-338.

Singer, G., \& Collins, J. (1972). Dissipation of sensory aftereffects as a function of axon length. Journal of Experimental Psychology, 96, 194-198.

WALKER, J. (1978). Simple and contingent aftereffects in the kinesthetic perception of length. Journal of Experimental Psychology: Human Perception \& Performance, 4, 294-301.

WALKER, J., \& SHEA, K. (1974). A tactual size aftereffect contingent on hand position. Journal of Experimental Psychology, 103, 668-674.

Weintraub, D., Green, G., \& Herzog, T. (1973). Kinesthetic aftereffects day by day: Trends, task features, reliable individual differences. American Journal of Psychology, 86, 827-844.

Weintraub, D., \& Herzog, T. (1973). The kinesthetic aftereffect: Ritual versus requisites. American Joumal of Psychology, 86, 407-423.

WENDEROTH, P. (1970). A visual spatial aftereffect of surface slant. American Journal of Psychology, 83, 576-590.

Wertheimer, M., \& SHEeTs, C. A., JR. (1968). Effect of instructional set on kinesthetic figural aftereffects. Joumal of Experimental Psychology, 77, 692-695.

WiLson, J. (1965). Adaptation and repulsion in the figural after-effect. Quarterly Journal of Experimental Psychology, 17, 1-13.

\section{NOTES}

1. Perhaps a difference between $\mathrm{I}>\mathrm{T}$ and $\mathrm{I}=\mathrm{T}$ would emerge if the size difference between $I$ and $T$ in the former condition were greater than what we used. Charles and Duncan (1959), Krauskopf and Engen (1960), and Pressey (1967), but not Costello, Beatriz, and Holland (1963), found that the size of KAE for I > T increases as the difference between $I$ and $T$ increases. Such an outcome would not contradict our conclusion that there are at least two types of KAE. Such an outcome would require that we modify the specifications of the form which these two types take: the induction phenomenon would now be seen as holding for $\mathrm{I}=\mathrm{T}$ and for $\mathrm{I}>\mathrm{T}$, but in the latter case, only when the difference between $I$ and $\mathrm{T}$ is relatively small; the contrast effect would be seen as holding for $\mathrm{I}<\mathrm{T}$ and for I $>\mathrm{T}$ but, in the latter instance, only when the difference between I and $\mathrm{T}$ was relatively large.

2. Given that the effect observed for $I=T$ appears to be a true aftereffect, the question arises as to how other variables affect this condition. We thank an anonymous reviewer for pointing out that one valuable direction for follow-up research might involve exploring the effect of variation in inspection time. Bakan et al. (1962) and Pressey (1967) found, for $\mathrm{I}<\mathrm{T}$ and for $\mathrm{I}>\mathrm{T}$, respectively, that the magnitude of $\mathrm{KAE}$ increases with increase in inspection time.

(Manuscript received August 16, 1985; revision accepted for publication January 1, 1986.) 